\title{
Activation of the Sonic Hedgehog pathway in thyroid neoplasms and its potential role in tumor cell proliferation
}

\author{
Xiulong $X u^{1}$, Helen Ding ${ }^{1}$, Geetha Rao ${ }^{1}$, Shalini Arora ${ }^{1}$, \\ Constantine $P$ Saclarides ${ }^{1}$, Joseph Esparaz ${ }^{1}$, Paolo Gattuso ${ }^{2}$, \\ Carmen C Solorzano ${ }^{1, t}$ and Richard A Prinz ${ }^{1, t}$
}

\author{
Departments of ${ }^{1}$ General Surgery and ${ }^{2}$ Pathology, Rush University Medical Center, 1653 West Congress Parkway, Chicago, Illinois \\ 60612, USA \\ (Correspondence should be addressed to XXu; Email: xxu@ rush.edu) \\ ${ }^{\dagger}$ (C C Solorzano is now at Division of Surgical Oncology and Endocrine Surgery, Vanderbilt University Medical Center, Nashville, \\ Tennessee 37232, USA) \\ ${ }^{\ddagger}$ (R A Prinz is now at Department of Surgery, NorthShore University Health System, Evanston, Illinois 60201, USA)
}

\begin{abstract}
The sonic hedgehog $(\mathrm{SHH})$ pathway is activated in several types of malignancy and plays an important role in tumor cell proliferation and tumorigenesis. SHH binding to a 12-pass transmembrane receptor, Patched (PTCH), leads to freeing of Smoothened (SMO) and subsequent activation of GLI transcription factors. In the present study, we analyzed the expression of SHH, PTCH, SMO, and GLI1 in 31 follicular thyroid adenomas (FTA), 8 anaplastic thyroid carcinomas (ATC), and 51 papillary thyroid carcinomas (PTC) by immunohistochemical staining. More than $65 \%$ of FTA, PTC, and ATC specimens stained positive for SHH, PTCH, SMO, and GLI. However, the expression of the genes encoding these four molecules did not correlate with any clinicopathologic parameters, including the age, gender, the status of BRAF gene mutation, tumor stage, local invasion, and metastasis. Three thyroid tumor cell lines (KAT-18, WRO82, and SW1736) all expressed the genes encoding these four molecules. 5-Bromo-2deoxyuridine labeling and MTT cell proliferation assays revealed that cyclopamine (CP), an inhibitor of the SHH pathway, was able to inhibit the proliferation of KAT-18 and WRO82 cells more effectively than SW1736 cells. CP led to the arrest of cell cycle or apoptosis. Knockdown of SHH and GLI expression by miRNA constructs that target SHH or GLI mRNA in KAT-18 and SW1736 cells led to the inhibition of cell proliferation. Our results suggest that the $\mathrm{SHH}$ pathway is widely activated in thyroid neoplasms and may have potential as an early marker of thyroid cancer or as a potential therapeutic target for thyroid cancer treatment.
\end{abstract}

Endocrine-Related Cancer (2012) 19 167-179

\section{Introduction}

Smoothened (SMO) is a seven-pass transmembrane molecule whose signaling function is suppressed by pairing with a transporter-like protein Patched $(\mathrm{PTCH}$; Taipale \& Beachy 2001, Hooper \& Scott 2005, van den Brink 2007). The engagement of PTCH with its ligand, Sonic hedgehog $(\mathrm{SHH})$, leads to freeing of SMO and subsequently activation of a family of latent transcriptional factors, the Cubitus interruptus/GLI (GLI; Taipale \& Beachy 2001, Hooper \& Scott 2005, van den Brink 2007). Recent studies have shown that the SHH pathway plays an important role in tumorigenesis and cancer formation (Taipale \& Beachy 2001, Hooper \& Scott 2005, van den Brink 2007). Inactivating mutations of the $\mathrm{PTCH}$ gene were found to be responsible for the inherited cancer predisposition disorder Gorlin or the nevoid basal cell carcinoma syndrome (Xie et al. 1998). Ligand-dependent activation of the SHH pathway has been demonstrated in breast (Kubo et al. 2004), prostate (Karhadkar et al. 2004, Sanchez et al. 2004), esophageal, gastric, and pancreatic carcinoma (Berman et al. 2003, Thayer et al. 2003). 
Blockade of the SHH pathway by cyclopamine (CP), an antagonist that binds SMO, can lead to the inhibition of cell proliferation (Berman et al. 2003, Thayer et al. 2003) and growth of several types of tumors such as pancreatic cancer implanted as xenografts in nude mice (Berman et al. 2003, Thayer et al. 2003). A recent clinical trial revealed that GDC-0449, an orally active small molecule that targets the hedgehog pathway, appears to have antitumor activity in locally advanced or metastatic basal cell carcinoma (Von Hoff et al. 2009).

Tumors derived from thyroid epithelial cells display diverse neoplastic phenotypes, including benign follicular adenomas, well-differentiated papillary and follicular carcinomas, and aggressive anaplastic carcinomas (Kondo et al. 2006). Molecular genetic studies have demonstrated that numerous oncogenes such as $R A S$, $B R A F$, and $R E T /$ papillary thyroid carcinomas $(P T C)$ are frequently mutated or rearranged in thyroid cancer (Kondo et al. 2006). Inhibitors of these mutated gene products are currently being developed as novel anticancer drugs for thyroid cancer treatment (Cohen et al. 2008, Gupta-Abramson et al. 2008). The discovery of other dysregulated pathways critical for thyroid tumor development may offer new therapeutic targets for thyroid cancer treatment. In this study, we report that the SHH pathway is activated in thyroid neoplasms and can contribute to increased cell proliferation.

\section{Materials and methods}

\section{Tumor specimens and patient information}

Paraffin-embedded tumor blocks from patients with thyroid neoplasms were retrieved from the Department of Pathology after approval by the Institutional Review Board of Rush University Medical Center. A total of 90 specimens, all with adequate clinical and pathological information, were studied. These include 31 follicular adenomas, 51 papillary carcinomas, and 8 anaplastic carcinomas. Nine fresh tissue specimens, including seven PTC, one normal thyroid, and a Hurthle cell adenoma from a single patient, were used for analysis of SHH expression by western blot analysis. These fresh tumor samples were not overlapping with 90 specimens used in immunohistochemical staining.

\section{Immunohistochemical staining of SHH, PTCH, SMO, and GLI1 in thyroid tumor tissues}

Tissue sections were de-waxed with xylene and rehydrated. Slides were treated in $1 \% \mathrm{H}_{2} \mathrm{O}_{2}$ in methanol for $30 \mathrm{~min}$ at room temperature followed by antigen retrieval in $6 \mathrm{M}$ urea in a microwave for $30 \mathrm{~min}$. Cooled slides were rinsed with PBS. Sections were blocked with 5\% normal goat serum in PBS for $30 \mathrm{~min}$ at room temperature followed by $1 \mathrm{~h}$ incubation with antibodies against SHH (EP1190Y; Novus Biologicals, Inc., Littleton, $\mathrm{CO}, \mathrm{USA}), \mathrm{PTCH}$ (H0267, sc-9016; Santa Cruz Biotechnology, Inc., San Diego, CA, USA), SMO (H-300, sc-13943; Santa Cruz Biotechnology, Inc.), and GLI1 (H-300, sc20687; Santa Cruz Biotechnology, Inc.) in PBS. After washing three times in PBS, the sections were incubated with biotinylated goat anti-rabbit $\mathrm{IgG}$ followed by streptavidin-conjugated HRP. Color development was done with diaminobenzidine substrate (Sigma). Slides were counterstained with Mayer's hemotoxylin for $2 \mathrm{~min}$, dehydrated, and mounted. Two investigators (X X and $\mathrm{P} G$ ) graded SHH, PTCH, SMO, and GLI1 expression in a blinded fashion. SHH, PTCH, SMO, and GLI1 were graded as negative $(-)$, no signal at all; positive $(+)$, with signal in $>20 \%$ of tumor cells; strongly positive $(++)$, with strong signal in more than $50 \%$ of tumor cells; and very strongly positive $(+++)$, with very strong signal in $>80 \%$ of tumor cells.

\section{Cell lines}

Three thyroid tumor cell lines were used in this study, including WRO82, an FTC cell line (provided by Dr Guy J F Juillard at University of California at Los Angeles), and two anaplastic thyroid carcinomas (ATC) cell lines, KAT-18 and SW1736 (provided by Dr Kenneth B Ain, University of Kentucky Medical Center, Lexington, KY, USA; Ain et al. 1997). The status of BRAF gene mutations in these three cell lines used in our study (Xu et al. 2003) is consistent with two previous publications (Kimura et al. 2003, Namba et al. 2003). Of note, WRO82 cells is a follicular thyroid carcinoma cell line that does not have BRAF mutation (Kimura et al. 2003, Namba et al. 2003, Xu et al. 2003). To validate the identity of these three thyroid tumor cell lines used in our study, short tandem repeats (STR) were commercially profiled by Genetica DNA Laboratories, Inc. (Cincinnati, OH, USA). We found that the STR profiles of SW1736 (passage 5) and KAT-18 (passage 22) were identical as previously reported (Schweppe et al. 2008). However, WRO82 cells (passage 70) had a unique STR profile (D2S1358, 23; vWA, 16; FGA, 22.2 and 23; Amelogenix, X; D8S1179, 11 and 16; D21S11, 29; D18S51, 13; D5S818, 12; D13S317, 9; and D7S820, 8 and 12). Schweppe et al. (2008) stated that a different clone of WRO82 cells was used in their study; that clone harbors a V600E BRAF gene mutation and does not express TTF-1. MPANC-96 cells (a pancreatic cancer 
cell line) were purchased from American Type Culture Collection (Manassas, VA, USA). All tumor cell lines were grown in complete RPMI-1640 medium containing $10 \%$ fetal bovine serum.

\section{RT-PCR}

Total cellular RNA was isolated from cell lines with TRIzol (Life Technologies, Inc.) and quantified by u.v. absorption. After reverse transcription of $500 \mathrm{ng}$ total RNA with oligo(dT) priming, the resulting singlestranded cDNA was amplified using TaqDNA polymerase (Life Technologies, Inc.). Of note, the forward and reverse primers for each gene were located in different exons, thus excluding the possibility to amplify a PCR product from contaminated genomic DNA. The PCR was set with an initial denaturation of 2 min at $94{ }^{\circ} \mathrm{C}$ and subsequent 30 cycles of denaturation for $45 \mathrm{~s}$ at $94{ }^{\circ} \mathrm{C}$, annealing for $45 \mathrm{~s}$ at $55^{\circ} \mathrm{C}$, and extension for $1 \mathrm{~min}$ at $72{ }^{\circ} \mathrm{C}$.

\section{SHH and GLI1 knockdown}

The SHH and GLI1 hairpin DNA oliognucleotides were synthesized and cloned into a microRNA expression vector, pcDNA6.2/GW-miR, according to the manufacturer's instruction (Invitrogen). The same expression vector encoding an miRNA sequence targeting $\beta$-galactosidase was included as a negative control. Plasmid DNA was purified by using the Qiagen MiniPreparation kit (Qiagen). The sequences of the inserted oligonucleotides were verified by DNA sequencing. SW1736 and KAT-18 cells seeded in a six well plate were transiently transfected with FuGENE6 (Roche Diagnostic $\mathrm{GmbH}$ ). After incubation for $48 \mathrm{~h}$, the cells were trypsinized and replated in a 96 well plate for cell proliferation assay at $96 \mathrm{~h}$ after transfection. Alternately, transfected cells were replated into a $60 \mathrm{~mm}$ dish with coverslips. After overnight incubation, the cells were pulsed for $6 \mathrm{~h}$ with $10 \mu \mathrm{M}$ 5-bromo-2-deoxyuridine (BrdU). The coverslips were collected and fixed in methanol for $10 \mathrm{~min}$ at $4{ }^{\circ} \mathrm{C}$ and used for analysis of SHH and GLI1 expression or BrdU labeling.

\section{Western blot}

Nine fresh tissues, including seven PTC, a Hurthle adenoma, and its matched normal thyroid, $50 \mathrm{mg} / \mathrm{sample}$ each, were homogenized in $500 \mu \mathrm{l} \mathrm{NP}-40$ lysis buffer (50 mM Tris- $\mathrm{HCl}$ (pH 8.0), $150 \mathrm{mM} \mathrm{NaCl}, 1 \%$ NP-40, $5 \mathrm{mM}$ EDTA, $10 \mu \mathrm{g} / \mathrm{ml}$ aprotinin, $10 \mu \mathrm{g} / \mathrm{ml}$ leupeptin, and $1 \mathrm{mM}$ phenylmethylsulphonyl fluoride). Thyroid tumor cell lines grown in six well plates were harvested and lysed in NP-40 lysis buffer. After incubation on ice for $30 \mathrm{~min}$, the cell lysates were prepared by spinning down at $4{ }^{\circ} \mathrm{C}, 16100 \mathrm{~g}$ for $15 \mathrm{~min}$. For detection of GLI1, TTF-1, and TTF-2, total cell lysates were prepared by directly lysing tissue or cells in $2 \times$ sample buffer. Cell lysates were extracted by passing through an insert of QIAshredder (Qiagen, Inc., Valencia, CA, USA). After electrophoresis and transfer onto Immobilon membrane, SHH, TTF-1, TTF-2, GLI1, and actin were detected by their specific antibodies, followed by HRPconjugated goat anti-rabbit IgG and SuperSignal Western Pico ECL substrate (Pierce Chemical Co., Rockford, IL, USA). A rabbit monoclonal anti-SHH antibody (EP1190Y) was purchased from Novus Biologicals, Inc. Antibodies against $\beta$-actin, TTF-1, and TTF-2 were purchased from Santa Cruz Biotechnology, Inc. Rabbit anti-GLI1 antibody was purchased from Cell Signaling Technology (Danver, MA, USA) or from Abcam (Cambridge, MA, USA).

\section{Immunofluorescence staining}

Tumor cell lines grown on coverslips were washed three times with cold PBS and fixed with cold methanol at $4{ }^{\circ} \mathrm{C}$ for $10 \mathrm{~min}$. Coverslips were blocked with $5 \%$ normal goat serum for $30 \mathrm{~min}$ at room temperature. The molecules of the SHH pathways were detected by the same specific antibodies used in immunohistochemistry (IHC) staining followed by fluorescein-conjugated goat anti-rabbit IgG. For BrdU staining, the cells grown on coverslips were first pulsed with $10 \mu \mathrm{M}$ BrdU for $6 \mathrm{~h}$. The cells were harvested, fixed with ethanol, denatured with $2 \mathrm{M} \mathrm{HCl}$ for $5 \mathrm{~min}$ at room temperature followed by neutralization with $0.1 \mathrm{M}$ borate buffer $(\mathrm{pH}$ 8.5). After rinsing and blocking with normal mouse serum, the coverslips were stained with an Alexa Fluor 488-conjugated anti-BrdU monoclonal antibody (BD Bioscience, Franklyn Lakes, NJ, USA). The coverslips were mounted with $50 \%$ glycerin in PBS containing antifade reagent 1,4-diazabicyclo[2.2.2] octane $(25 \mathrm{mg} / \mathrm{ml})$ and 4,6-diamidino-2-phenylindole $(0.5 \mathrm{mg} / \mathrm{ml}$; Sigma Chemical Co.). Alexa Fluor 488conjugated mouse IgG was included as a control. SHH, PTCH, SMO, and GLI1 expression and BrdU incorporation were examined under an Olympus BX41TF fluorescence microscope connected to a digital camera.

\section{MTT assay}

Thyroid tumor cell lines were grown in complete RPMI1640 medium supplemented with $10 \%$ fetal bovine serum. The cells were seeded in 96 well plates at the density of 2000/well in the presence of DMSO (0.2\%), 3 or $9 \mu \mathrm{M} \mathrm{CP}$ (Toronto Research Chemicals, Inc., North York, ON, Canada) or 5 or $25 \mu \mathrm{M}$ HhAntag 
(Genentech, Inc., South San Francisco, CA, USA) dissolved in DMSO. MPANC-96 cells were used as a positive control. After incubation for $96 \mathrm{~h}$, cell proliferation was monitored by using a CellTiter 96 nonradioactive cell proliferation assay kit (MTT; Promega) following the manufacturer's instruction. SW1736 cells transfected with miRNA constructs were replated onto a 96 well plate and similarly analyzed for cell proliferation at $96 \mathrm{~h}$ after transfection.

\section{DNA replication and cell cycle analysis}

SW1736, KAT-18, and WRO82 cells were grown in complete RPMI-1640 medium with $10 \%$ fetal bovine serum in $60 \mathrm{~mm}$ dishes. Upon $40 \%$ confluence, the cells were treated with vehicle or with CP $(9 \mu \mathrm{M})$ for $48 \mathrm{~h}$. Cells were pulsed with $10 \mu \mathrm{M}$ BrdU for $3 \mathrm{~h}$. Cells were harvested, denatured with $2 \mathrm{M} \mathrm{HCl}$ for $5 \mathrm{~min}$ at room temperature followed by neutralization with $0.1 \mathrm{M}$ borate buffer ( $\mathrm{pH}$ 8.5). After washing and blocking with normal mouse serum, the cells were stained with an Alexa Fluor 488-conjugated anti-BrdU monoclonal antibody (BD Bioscience), followed by analysis in a flow cytometer. Alexa Fluor 488-conjugated mouse IgG was included as a control. For cell cycle analysis, the cells were harvested and fixed with $2 \mathrm{ml}$ cold $70 \%$ ethanol in PBS overnight at $4{ }^{\circ} \mathrm{C}$. Fixed cells were then washed three times with PBS, treated with RNaseA $(100 \mu \mathrm{g} / \mathrm{ml}$ in $0.5 \mathrm{ml}$ PBS $)$. After incubation at room temperature for $30 \mathrm{~min}$, cells were stained with $2.5 \mu \mathrm{l}$ propidium iodine $(10 \mathrm{mg} / \mathrm{ml})$ and immediately analyzed for DNA content in a flow cytometer.

\section{Statistical analyses}

$\chi^{2}$ or Fisher's exact test was used to determine whether there were significant differences in the expression of SHH, PTCH, SMO, and GLI1 among follicular thyroid adenomas (FTA), PTC, and ATC (Table 1); and whether there were significant differences in SHH, $\mathrm{PTCH}, \mathrm{SMO}$, and GLI1 expression among patients of different age and gender; and whether SHH, PTCH, and SMO expression correlated with tumor pathologic stage and the status of BRAF mutation (Table 2). Unpaired Student's $t$-test was used to determine if there was a significant difference in the cell proliferation. A $P$ value $<0.05$ was considered statistically significant. All statistics were performed with SigmaStat 3 software (Richmond, CA, USA).

\section{Results}

\section{Detection of SHH pathway components in thyroid tumors}

We conducted IHC staining to analyze the expression of four molecules in the SHH pathway, including $\mathrm{SHH}$, PTCH, SMO, and GLI1 in thyroid neoplasms. As shown in Fig. 1A, SHH, PTCH, SMO, and GLI1 were not present in normal thyroid follicular epithelial cells but were strongly expressed in an FTA, a PTC, and an ATC specimen. SHH, PTCH, and SMO signals were largely present in cytoplasm; whereas GLI1 signals appeared to be in both cytoplasm and nuclei. The section of a pancreatic cancer used as a positive control stained for GLI1 expression, whose signals were largely in nuclei, was shown in Fig. 1B, e. Normal rabbit IgG served as a negative control (Fig. 1B, f). Normal thyroid follicles in the vicinity of SHH-, SMO-, PTCH-, and GLI1-positive tumor cells were negative (Fig. 1B, a, b, c and d). Among 22 PTC and 15 FTA tumor sections with clearly identifiable normal thyroid follicular epithelial cells, SHH, SMO, PTCH, and GLI1 were stained negative or with only very minimal signals. Examples of SHH, PTCH, SMO, and GLI1 expression in PTC graded as negative $(-)$, positive $(+)$, strongly positive $(++)$, and very strongly positive $(+++)$ are given in Fig. 1C. Western blot analysis revealed that $\mathrm{SHH}$ expression was detected in five of seven PTC as a $47 \mathrm{kDa}$ unprocessed SHH and a processed $19 \mathrm{kDa}$ protein in six of seven PTC (Fig. 1D). SHH was expressed at very low level in a normal thyroid tissue but was highly expressed in a matched Hurthle cell adenoma. GLI1 was detected as a $150 \mathrm{kDa}$ protein in four of seven PTC (\#1, \#2, \#4, \#5) and a Hurthle cell adenoma. Anti-PTCH and anti-SMO antibodies used in IHC were unable to recognize denatured PTCH and SMO was transferred onto PVDF membrane in western blot, either due to low affinity or low abundance of proteins in the tissue lysates.

Table $1 \mathrm{SHH}, \mathrm{PTCH}$, and SMO expression in thyroid tumors

\begin{tabular}{|c|c|c|c|c|c|c|c|c|c|c|c|c|c|c|c|c|c|}
\hline & \multirow[b]{2}{*}{ Total } & \multicolumn{4}{|c|}{ SHH } & \multicolumn{4}{|c|}{ PTCH } & \multicolumn{4}{|c|}{ SMO } & \multicolumn{4}{|c|}{ GLI } \\
\hline & & - & + & ++ & +++ & - & + & ++ & +++ & - & + & ++ & +++ & - & + & ++ & +++ \\
\hline FTA & 31 & 7 & 5 & 5 & 14 & 7 & 8 & 9 & 7 & 7 & 5 & 6 & 13 & 10 & 7 & 7 & 7 \\
\hline PTC & 51 & 12 & 14 & 15 & 10 & 18 & 9 & 9 & 15 & 17 & 11 & 9 & 14 & 9 & 17 & 14 & 11 \\
\hline ATC & 8 & 1 & 3 & 0 & 4 & 1 & 0 & 2 & 5 & 1 & 2 & 1 & 4 & 1 & 0 & 2 & 5 \\
\hline
\end{tabular}




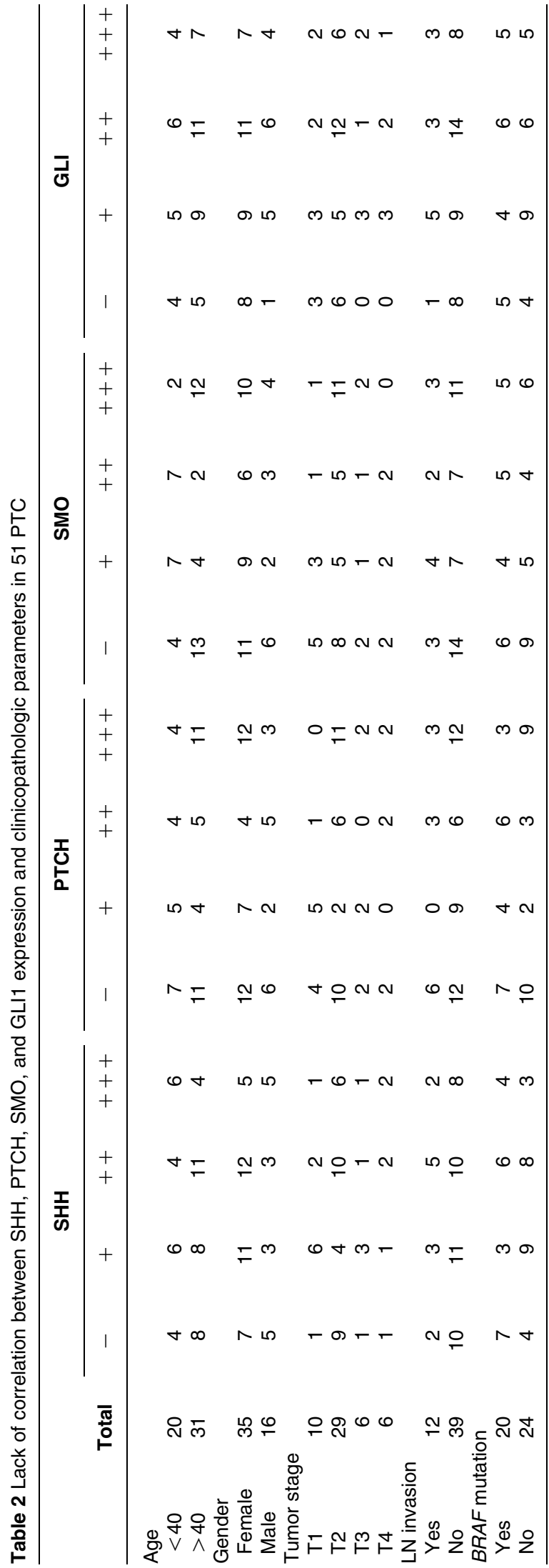

\section{SHH expression}

Among 31 FTA specimens, SHH expression was graded as negative $(-)$ in seven, positive $(+)$ and strongly positive $(++)$ in five each, and very strongly positive $(+++)$ in fourteen (Table 1). Among 51 PTC specimens, SHH expression was graded as negative $(-)$ in 12 , positive $(+)$ in 14 , strongly positive $(++)$ in 15 , and very strongly positive $(+++)$ in 10 (Table 1$)$. Among eight ATC specimens, SHH expression was graded as negative $(-)$ in one, positive $(+)$ in three, and very strongly positive $(+++)$ in four (Table 1).

\section{PTCH expression}

Among 31 FTA specimens, PTCH expression was graded as negative $(-)$ in 7 , positive $(+)$ in 8 , strongly positive $(++)$ in 9 , and very strongly positive $(+++)$ in 7 (Table 1). Among 51 PTC specimens, PTCH expression was graded as negative $(-)$ in 18 , positive $(+)$ in 9 , strongly positive $(++)$ in 9 , and very strongly positive $(+++)$ in 15 (Table 1$)$. Among eight ATC specimens, PTCH expression was graded as negative $(-)$ in one, strongly positive $(++)$ in two, and very strongly positive $(+++)$ in five (Table 1$)$.

\section{SMO expression}

Among 31 FTA specimens, SMO expression was graded as negative $(-)$ in 7 , positive $(+)$ in 5 , strongly positive $(++)$ in 6 , and very strongly positive $(+++)$ in 3 (Table 1). Among 51 PTC specimens, SMO expression was graded as negative $(-)$ in 17 , positive $(+)$ in 11 , strongly positive $(++)$ in 9 , and very strongly positive $(+++)$ in 14 (Table 1 ). Among eight ATC specimens, SMO expression was graded as negative $(-)$ in one, positive $(+)$ in two, strongly positive $(++)$ in two, and very strongly positive $(+++)$ in five (Table 1$)$.

\section{GLI1 expression}

Among 31 FTA specimens, GLI expression was graded as negative $(-)$ in 10 , positive $(+)$ in 7 , strongly positive $(++)$ in 7 , and very strongly positive $(+++)$ in 7 (Table 1). Among 51 PTC specimens, GLI expression was graded as negative $(-)$ in 9, positive $(+)$ in 17 , strongly positive $(++)$ in 14 , and very strongly positive $(+++)$ in 11 (Table 1 ). Among eight ATC specimens, GLI expression was graded as negative $(-)$ in one, strongly positive $(++)$ in two, and very strongly positive $(+++)$ in five (Table 1). 

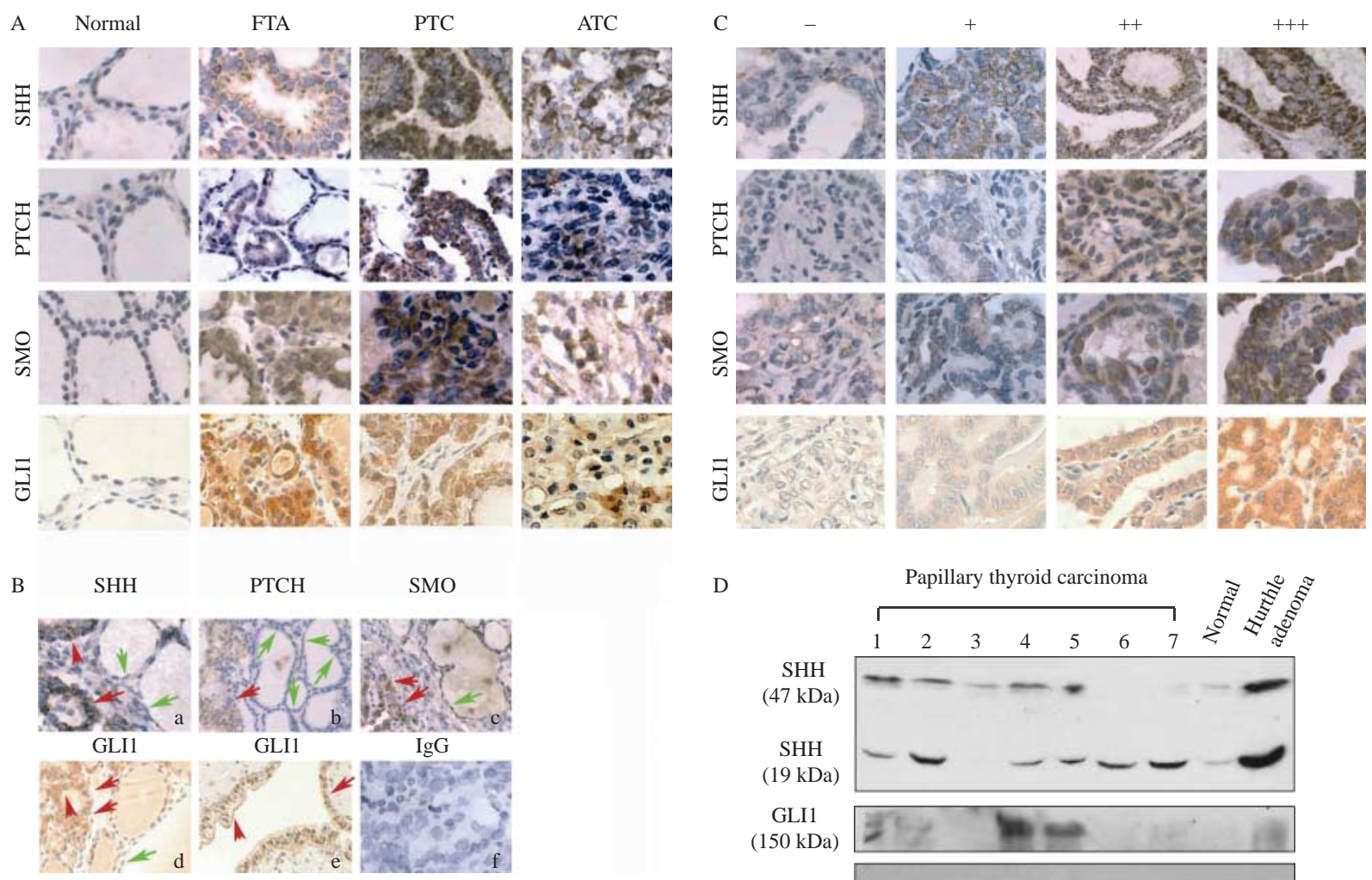

$\mathrm{D}$

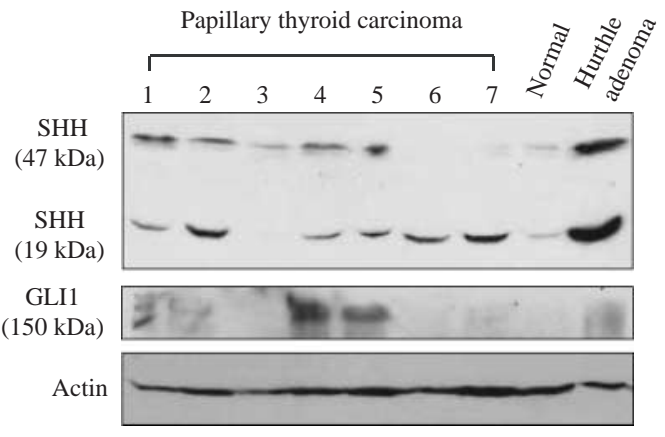

Figure $1 \mathrm{IHC}$ staining of $\mathrm{SHH}, \mathrm{PTCH}, \mathrm{SMO}$, and GLI1. (A) $\mathrm{SHH}, \mathrm{PTCH}, \mathrm{SMO}$, and GLI1 expression was analyzed by IHC staining with their specific antibodies in normal thyroid follicles, FTA, PTC, and ATC. SHH, PTCH, SMO, and GLI1 were not detected in normal thyroid epithelial cells but were expressed in FTA, PTC, and ATC. (B) Negative staining for (a) SHH, (b) PTCH, (c) SMO, and (d) GLI1 on normal thyroid epithelial cells (green arrows) in the vicinity of tumor cells (red arrows) that stained positive for SHH, $\mathrm{PTCH}, \mathrm{SMO}$, and GLI1. Normal rabbit IgG was included as a (f) negative control. A pancreatic cancer specimen included as a (e) positive control is shown. Nuclear localization of GLI1 was indicated. (C) Examples of SHH, PTCH, SMO, and GLI graded as negative $(-)$, positive $(+)$, strongly positive $(++)$, and very strongly positive $(+++)$. (D) Western blot analysis of SHH expression in fresh tumor tissue. Fresh normal and tumor tissues $(50 \mathrm{mg} / \mathrm{sample}$ in $0.5 \mathrm{ml} \mathrm{NP}-40$ lysis buffer) were homogenized. Equal amounts of the cell lysates were analyzed for $\mathrm{SHH}$ expression by western blot analysis with a rabbit anti-SHH monoclonal antibody. In a duplicate membrane, $\beta$-actin was probed with a mouse monoclonal antibody as a loading control.

\section{Concomitant upregulation of the SHH pathway molecules and its relationship to clinicopathologic parameters}

It has been well established that activation of the $\mathrm{SHH}$ pathway leads to an autocrine upregulation of $\mathrm{SHH}$, PTCH, and GLI1 (Ruiz i Altaba et al. 2002). We found that the accordance rate between $\mathrm{SHH}$ and $\mathrm{PTCH}$ expression and between SHH and SMO expression was 77 and $79 \%$ respectively, the accordance rate between $\mathrm{PTCH}$ and SMO expression was $86 \%$. There was an overall accordance rate of $77 \%$ between GLI1 expression and $\mathrm{SHH}, \mathrm{PTCH}$, or SMO expression among 31 FTA; an overall accordance rate of 78, 71, and $71 \%$ between GLI1 expression and SHH, PTCH, or SMO expression respectively among $51 \mathrm{FTC}$, and an overall accordance rate of 75, 75, and $100 \%$ between GLI1 expression and SHH, PTCH, or SMO expression respectively among eight ATC. We did not find that the expression of SHH, PTCH, SMO, and GLI1 in PTC correlated with any clinicopathologic parameters, including patient's age, gender, tumor stage, lymph node invasion, and $B R A F$ gene mutation $(P>0.05$; Table 2). The frequency of SHH, PTCH, SMO, and GLI1 positivity was not significantly different between FTA and PTC $(P>0.05$; Table 1$)$.

\section{Expression of the SHH pathway components in thyroid tumor cell lines}

We next tested whether the genes of the SHH pathway were expressed in three thyroid tumor cell lines. RT-PCR revealed the presence of $S H H, P T C H, S M O$, and GLII mRNA in WRO82, SW1736, and KAT-18 cells (Fig. 2A). Western blot analysis revealed that SHH was detected with a molecular mass of $\sim 47 \mathrm{kDa}$ 
doublet (Fig. 2B, upper panel) in all three thyroid tumor cell lines. A cleaved $19 \mathrm{kDa} \mathrm{SHH}$ was detected only after a prolonged exposure (Fig. 2B). Of note, the ratios of 47 to $19 \mathrm{kDa} \mathrm{SHH}$ were much higher in these three tumor cell lines than that in fresh tumor tissues. GLI1 was detected as a $150 \mathrm{kDa}$ protein in all three cell lines. TTF-1 and TTF-2, two thyroid specific transcription factors, were detected in western blot with a molecular mass of 44 and $130 \mathrm{kDa}$ respectively, further confirming that these three thyroid tumor cell lines were of thyroid origin (Fig. 2C). Immunofluorescence (IF) staining confirmed the expression of $\mathrm{SHH}, \mathrm{PTCH}$, SMO, and GLI1 in all cell lines. The signals of $\mathrm{SHH}, \mathrm{PTCH}$, and SMO were mainly located in the cytoplasm, whereas GLI1 expression was largely located in the nuclei of all three cell lines. Normal rabbit IgG included as a negative control did not show any nonspecific signals (Fig. 2D).

\section{Inhibition of thyroid tumor cell proliferation by CP or HhAntag}

We next conducted MTT assay to determine whether $\mathrm{CP}$, an inhibitor of the SHH pathway, was able to inhibit the proliferation of three thyroid tumor cell lines. As shown in Fig. $3 \mathrm{~A}, \mathrm{CP}$ at 3 and $9 \mu \mathrm{M}$ inhibited the proliferation of KAT-18 and WRO82 cells in a dosedependent manner. SW1736 cells were less sensitive to $\mathrm{CP}$. When used at $9 \mu \mathrm{M}, \mathrm{CP}$ was able to significantly inhibit SW1736 cell proliferation by $24 \%(P<0.05)$. MPANC-96 cells, a pancreatic cancer cell line, were included as a positive control. $\mathrm{CP}$ at $9 \mu \mathrm{M}$ reduced MPANC-96 cell proliferation by $48 \%$. Similar observations were made with HhAntag (GDC-0449), another inhibitor of the SHH pathway. HhAntag at 5 and $25 \mu \mathrm{M}$ inhibited the proliferation of KAT-18 and WRO82 cells but had little effect on SW1736 cell proliferation (data not shown). The concentrations of CP and HhAntag (at micromolar levels) required to inhibit thyroid tumor cell proliferation are within the range required to inhibit the proliferation of $\mathrm{SHH}$-activated lung, melanoma, and medulloblastoma cell lines (Romer et al. 2004, Stecca et al. 2007, Yuan et al. 2007). We next conducted BrdU-labeling assay to determine whether $\mathrm{CP}$ was able to inhibit DNA replication. As shown in Fig. 3B, BrdU incorporation into genomic DNA was significantly inhibited in WRO82 and KAT-18 cells treated with $\mathrm{CP}(9 \mu \mathrm{M})$. Consistently, CP was less effective in suppressing DNA replication of SW1736, compared to another two thyroid tumor cell lines (Fig. 3B). To test whether CP inhibited the proliferation of thyroid tumor cell lines by arresting cell cycle progression, the cells cultured in the absence or presence of $\mathrm{CP}(9 \mu \mathrm{M})$ for $48 \mathrm{~h}$ were analyzed for DNA content by using propidium iodine staining. CP was able to arrest cell cycle in the G1 phase in WRO82 more effectively than SW1736 cells (Fig. 3C). Percents of WRO82 cells in the G1, M, and G2/M phases in DMSO-treated cells vs CP-treated cells were 68, 13, and $18 \%$ vs 75,10 , and $13 \%$ respectively. Percents of SW1736 cells in the G1, M, and G2/M phases in DMSO-treated cells vs CP-treated cells were 62, 19, and $19 \%$ vs 67,15 , and $18 \%$, respectively. Interestingly, we found that $\mathrm{CP}$ treatment led to a significant increase in the presence of KAT-18 cells in sub-G1 phase, suggesting that the cells became apoptotic.

\section{Inhibition of cell proliferation by SHH and GLI1 gene knockdown}

The concentrations of $\mathrm{CP}$ and HhAntag required to inhibit the SHH-induced promoter activation is
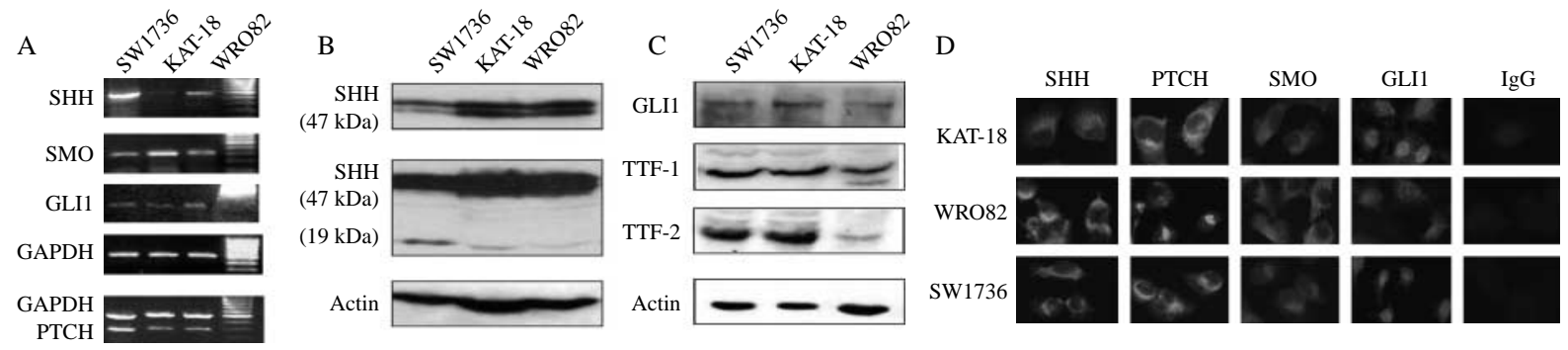

Figure 2 Detection of SHH pathway gene expression in three thyroid tumor cell lines. (A) RT-PCR. Total cellular RNA was extracted and analyzed for the expression of SHH, PTCH, SMO, and GLI1 mRNA by RT-PCR. GAPDH was included as a control. For analysis of PTCH mRNA, the primers for amplifying GAPDH were also included in the PCR. PCR products were analyzed on $1.5 \%$ agarose gels and visualized by ethidium bromide staining under a u.v. transilluminator. (B and C) Western blot. Lysates of three thyroid tumor cell lines were loaded into polyacrylamide gels. After electrophoresis, proteins were transferred onto PVDF membranes followed by detection with antibodies against SHH and $\beta$-actin (B), GLI1, TTF-1, TTF-2, and $\beta$-actin (C). (D) IF analysis of the expression of the molecules of the SHH pathway in thyroid tumor cell lines. Three thyroid tumor cell lines grown on coverslips were fixed with cold methanol for $5 \mathrm{~min}$ and analyzed for the expression of SHH, PTCH, SMO, and GLI1 with their specific antibodies, followed by using FITC-conjugated goat anti-rabbit IgG. Normal rabbit IgG was included as a negative control. 
generally much lower (at nanomolar range) than that required to inhibit cell proliferation (at micromolar range) (Romer et al. 2004, Mas \& Ruiz i Altaba 2010). Several studies have challenged whether CP used at micromolar concentration may have inhibited cell proliferation by its off-target effect (Yauch et al. 2008, Zhang et al. 2009). To further test whether the SHH pathway and GLI1 were involved in thyroid tumor cell proliferation, we used a genetic approach to determine if $S H H$ and GLII knockdown will lead to the inhibition of cell proliferation on two tumor cell lines, SW1736 and KAT-18. Since GLI1 can be activated by Ras in an SHH-independent manner (Ji et al. 2007, NolanStevaux et al. 2009), the effect of GLII knockdown on SW1736 cell proliferation should reveal if GLII contributes to BRAF-mutated cell proliferation independent of the SHH pathway. SW1736 and KAT-18 cells were transiently transfected with two constructs of SHH- and GLI-miRNA each. SHH and GLI1 expression was monitored by IF staining. As shown in Fig. 4A, the signals of $\mathrm{SHH}$ expression were significantly reduced in SW1736 cells transfected with two SHH-miRNA constructs (SHH-miRNA 658 and 1201), compared to the cells transfected with control miRNA or two GLI1-miRNA constructs; whereas nuclear staining of GLI1 protein was significantly reduced in two GLI1-miRNA constructs (GLI-miRNA 760 and 1519)-transfected SW1736 cells. Suppression of SHH and GLI1 expression in miRNA-transfected SW1736 cells was also confirmed by western blot analysis (Fig. 4B). SW1736 cells transfected with two SHH-miRNA constructs (\#658 and \#1201) led to the inhibition of SHH expression, whereas SW1736 cells transfected with two GLI1miRNA constructs (\#760 and \#1519) led to decreased GLI1 expression. To determine if suppression of SHH and GLI1 expression led to the inhibition of cell proliferation, we first conducted BrdU-labeling experiments and found that after a 6-h pulse, BrdU incorporation was detected in almost $100 \%$ of the nuclei of control miRNA-transfected SW1736 cells (Fig. 4A, right column). In contrast, the number of BrdU-positive cells was significantly reduced in SHHmiRNA- and GLI1-miRNA-transfected cells (Fig. 4A). To further confirm the inhibitory effect of $\mathrm{SHH}$ and GLII knockdown on cell proliferation, we analyzed the proliferation of SW1736 cells by counting the cell number at $72 \mathrm{~h}$ after transient transfection. As shown in Fig. 4C, cell numbers in SW1736 cells transfected with two SHH-miRNA constructs were about 45 and $42 \%$ of the cells transfected with control miRNA (Fig. 4C). Cell numbers in SW1736 cells transfected with two GLI1-miRNA constructs were about 58 and $46 \%$ of the cells transfected with control miRNA (Fig. 4C). MTT assay revealed that suppression of SHH or GLI1 expression led to a significant inhibition of SW1736 proliferation (Fig. 4D). Cell proliferation was reduced in cells transfected with SHH- and GLI-miRNA by $\sim 40$ and $30 \%$ respectively. KAT-18 cells transiently transfected with two miRNA constructs that target SHH or GLI1 also led to a significant inhibition of cell proliferation (data not shown).

\section{Discussion}

In the present study, we examined the expression of four components of the SHH pathway, SHH, PTCH, SMO, and GLI1 in thyroid neoplasms. We found that these molecules were widely expressed not only in PTC and ATC but also in benign FTA. More than $65 \%$ of thyroid tumor samples were positive for these four molecules (Table 1). Additionally, we found that two thyroid papillary microcarcinomas expressed $\mathrm{SHH}$, PTCH, SMO, and GLI1 (data not shown). These observations suggest that the SHH pathway is activated in a very early stage of thyroid tumor development. This notion is in line with several other studies showing increased expression of the members of the $\mathrm{SHH}$ pathway in endometrial hyperplasia (Feng et al. 2007), gastric adenomas (Lee et al. 2007), ovarian (Chen et al. 2007), and pancreatic cystadenomas (Thayer et al. 2003, Liu et al. 2007, Morton et al. 2007). Since there is no evidence available indicating that germ-line mutations of the PTCH gene in the nevoid basal cell carcinoma syndrome lead to an increased incidence of thyroid neoplasms, it appears that activation of the SHH pathway does not play a causal role in thyroid tumor development but may collaborate with other oncogenes to promote thyroid tumorigenesis.

A prior study from this lab showed that the frequency of SHH but not SMO and PTCH expression in a small group of 13 patients is higher in synchronous follicular adenomas than PTC (Nelson et al. 2010). Our current clinicopathological study showed that the levels of SHH, PTCH, SMO, and GLI1 expression were not significantly different among benign thyroid follicular adenomas, well-differentiated PTC, and poorly differentiated ATC, and among PTC at different tumor stages. In addition, we did not find any correlation between the status of the expression of the SHH pathway molecules and the invasive or metastatic potential of PTC. The activation of the SHH pathway may not be involved in thyroid tumor progression. These observations are consistent with previous studies showing that the expression of the molecules in the SHH pathway is not associated with the pathologic and histologic stage 

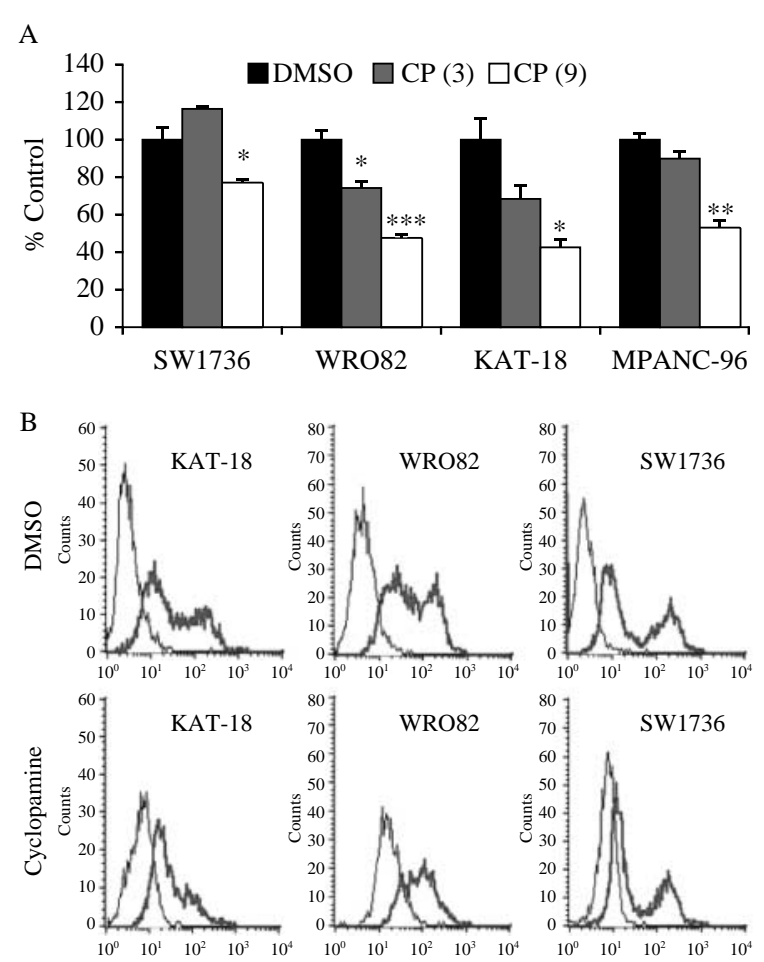

Fluorescence intensity
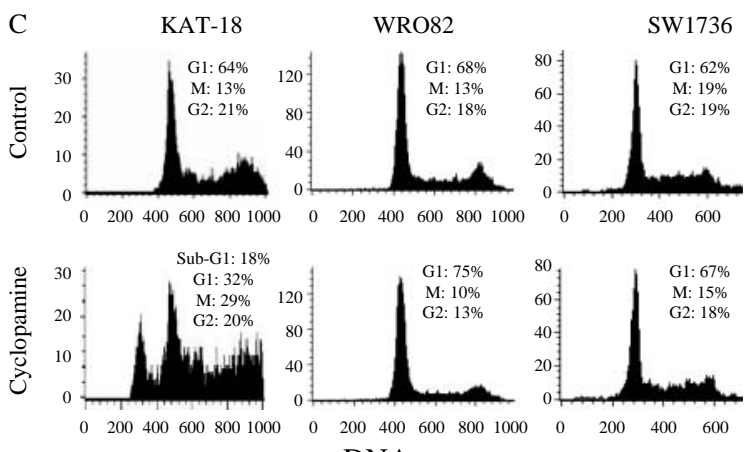

DNA content

Figure 3 Inhibition of cell proliferation by CP. (A) MTT assay. Three thyroid tumor cell lines and MPANC-96 (2000 cells/well), a pancreatic cancer cell line included as a positive control, were seeded in 96 well plates. Cells were treated with vehicle control or $\mathrm{CP}$ at 3 or $9 \mu \mathrm{M}$ for $96 \mathrm{~h}$. Cell proliferation was quantified by using an MTT cell proliferation kit. The data were presented as mean \pm s.D. from one of three experiments with similar results. ${ }^{\star} P<0.05 ;{ }^{\star \star} P<0.01 ;{ }^{\star \star \star} P<0.001$; (B) BrdU labeling. Cells grown in $60 \mathrm{~mm}$ dishes were treated with DMSO $(0.2 \%)$ or $\mathrm{CP}$ $(9 \mu \mathrm{M})$ for $48 \mathrm{~h}$. After pulsing with BrdU $(10 \mu \mathrm{M})$ for $3 \mathrm{~h}$, the cells were harvested and analyzed for BrdU incorporation by staining with an Alexa Fluor 488-conjugated anti-BrdU monoclonal antibody followed by flow cytometry (red line). An Alexa Fluor488-conjugated mouse IgG antibody was included as a negative control (blue line). (C) Inhibition of cell cycle progression by CP. Cells were similarly treated as in (B) except without pulsing with BrdU. Single cell suspensions were prepared and fixed with $2 \mathrm{ml}$ cold $70 \%$ ethanol in PBS overnight at $4{ }^{\circ} \mathrm{C}$. Cells were then treated with RNase A followed by labeling with propidium iodine. Cell cycle was analyzed in a flow cytometer. of breast (Kubo et al. 2004), ovarian (Feng et al. 2007), and prostate cancers (Sanchez et al. 2004).

The mechanisms of SHH pathway gene overexpression in a variety of malignancies are incompletely understood. Increased $\mathrm{SHH}$ expression in gastric cancer and its related lesions correlates with the altered SHH promoter methylation (Wang et al. 2006). Ma et al. (2006) reported that the $\mathrm{SHH}$ gene is amplified in esophageal cancer. Additional studies have shown that activation of several oncogene-mediated signaling pathways is involved in increased expression of $\mathrm{SHH}$ pathway molecules. For example, Ji et al. (2007) reported that $R A S$ or $B R A F$ gene mutation in pancreatic cancer cell lines leads to increased GLI1 transcriptional activity due to increased stability of GLI1 protein. MAP kinase activation due to $B R A F$ or $R A S$ gene mutation, RET/PTC rearrangements, or other genetic alterations in thyroid neoplasms is widespread. It remains unclear if the activation of the MAP kinase pathway in thyroid cancer may also contribute to increased GLI1 expression and its transcriptional activity, subsequently leading to increased expression of SHH pathway molecules. In addition, NF- $\kappa \mathrm{B}$ activation in thyroid neoplasms may also contribute to increased expression of SHH pathway molecules since several NF- $\kappa \mathrm{B}$ binding sites have been identified in the promoter of the $S H H$ gene (Kasperczyk et al. 2009). Moreover, a recent study demonstrated that SHH expression can be regulated by p63 (Caserta et al. 2006), a homologue of p53 that plays an important role in tumorigenesis and in maintenance and development of the epithelial stem cells. Interestingly, several prior studies have shown that p63 is overexpressed in thyroid cancer (Preto et al. 2002, Reis-Filho et al. 2003, Unger et al. 2003, Burstein et al. 2004). Taken together, overexpression of SHH pathway molecules may result from epigenetic changes of SHH pathway genes and/or depends on the activation of other oncogene signaling pathways or aberrant activation of some transcription factors such as NF- $\mathrm{B}$ or p63.

The expression of some genes involved in the SHH pathway can be regulated in an autocrine manner. For example, $P T C H$ gene mutation leads to upregulation of SHH gene expression (Unden et al. 1997). In an attempt to determine if overexpression of the $\mathrm{SHH}$ pathway molecules resulted from PTCH mutations, we analyzed 12 BRAF-negative PTC specimens for PTCH gene mutation in exons 13,14 , and 15 by directly sequencing the PCR-amplified fragments. Except for a polymorphism at nucleotide $2173 \mathrm{C} / \mathrm{T}$ (serine $\rightarrow$ proline) in one PTC specimen, no mutation was found in the hotspots of the PTCH gene that is frequently mutated in other types of tumors (X Xu, unpublished 
A
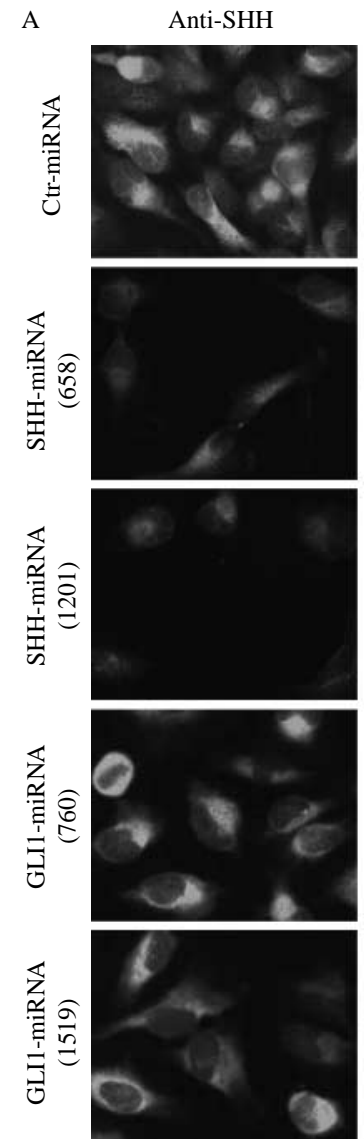

Anti-GLI1
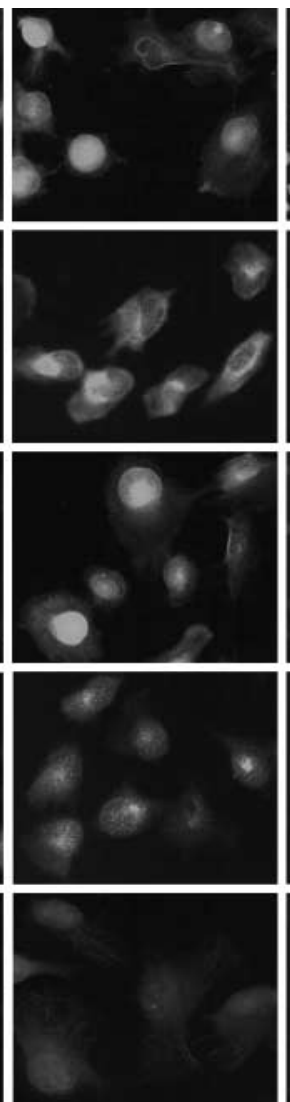

Anti-BrdU
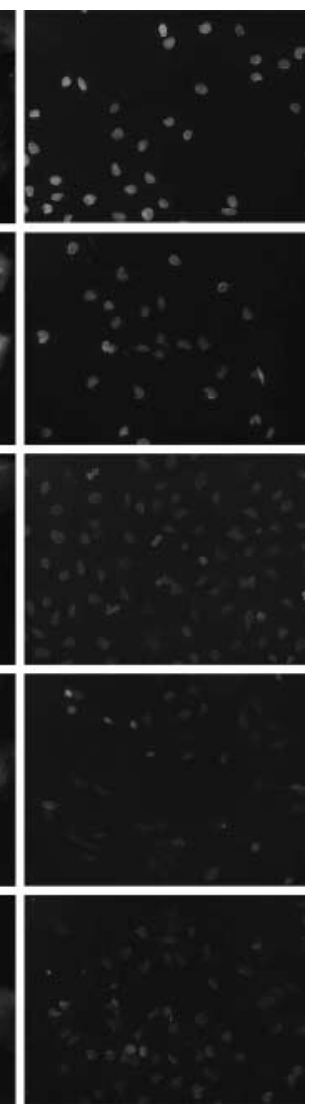

B
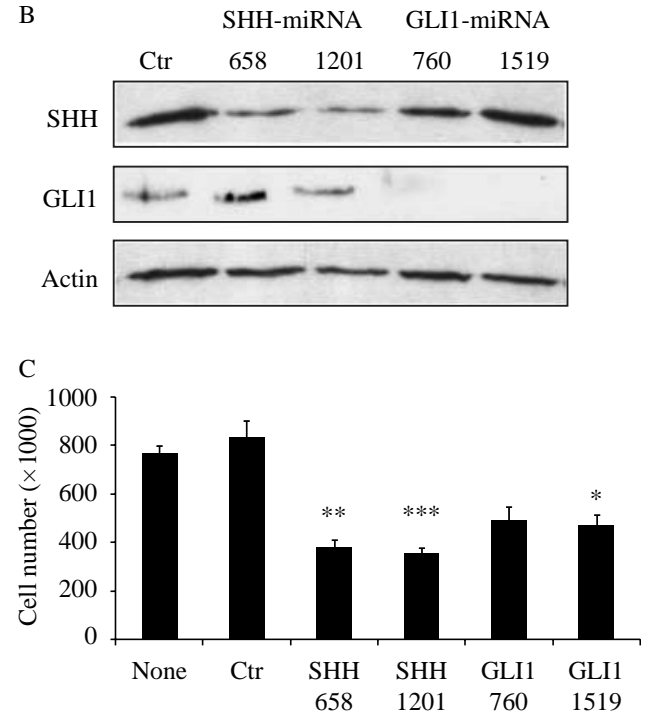

$\mathrm{D}$

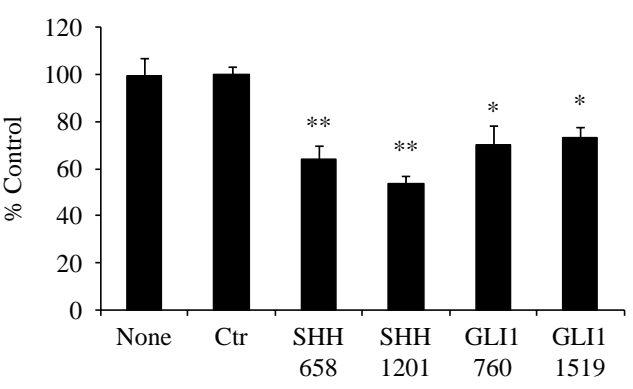

Figure 4 Inhibition of cell proliferation and cell cycle progression by SHH and GL/1 knockdown. (A) IF analysis of SHH and GLI1 expression and BrdU incorporation. SW1736 cells grown in six well plates were transiently transfected with a pcDNA6.2 control, two pcDNA/SHH-miRNA constructs that target SHH mRNA at 658 and 1201 nucleotides respectively, or two pcDNA/GLI1-miRNA plasmid DNA that target GLI1 mRNA at 760 and 1519 nucleotides respectively. After incubation for $48 \mathrm{~h}$, cells were trypsinized and seeded on coverslips. SHH and GLI1 expression was analyzed by IF staining with their specific antibodies as described in Fig. 2C. BrdU incorporation was analyzed by IF staining with an Alexa Fluor 488-labeled anti-BrdU mAb. The staining was visualized under a fluorescence microscope. (B) Western blot analysis of SHH and GLI1. SW1736 cells transiently transfected with control miRNA or two miRNA constructs targeting SHH or GLI1 were harvested and analyzed for SHH and GLI1 expression by western blot analysis as described in Fig. 2B. (C and D) Inhibition of cell proliferation by SHH and GLI1 knockdown. SW1736 cells transfected with control miRNA, SHH- or GLI-miRNA were analyzed for cell proliferation by counting the cell numbers at $72 \mathrm{~h}$ posttransfection (C) or by MTT assay in a 96 well plate (D). One representative of three experiments with similar results was shown. ${ }^{\star} P<0.05 ;{ }^{\star \star} P<0.01 ;{ }^{\star \star \star} P<0.001$.

data). SMO mutation in other tumor types is a rare event, and no hotspot mutation has been identified. Though we have not analyzed SMO mutations in thyroid neoplasms, it is less likely that widespread expression of the molecules of the SHH pathway results from $S M O$ gene mutations.

Activation of the SHH pathway can stimulate cell proliferation through the activation of GLI1 (Taipale \& Beachy 2001, Hooper \& Scott 2005). Its activation leads to increased transcription of several genes involved in DNA replication and cell cycle progression (Taipale \& Beachy 2001, Hooper \& Scott 2005). For example, Duman-Scheel et al. (2002) reported that activation of the SHH pathway leads to increased expression of cyclin D and E; Teh et al. (2002) reported that GLI1 activation leads to increased expression of FOXM1, a transcription factor involved in regulating cell growth, proliferation, longevity, and transformation. In addition, activation of the SHH pathway may suppress apoptosis by inducing the expression of antiapoptotic Bcl-2 (Bigelow et al. 2004). $\mathrm{CP}$ at concentrations ranging from 2 to $20 \mu \mathrm{M}$ is able to inhibit the proliferation of many tumor cell lines by arresting cell cycle progression though the suppression of cyclin D1 and the induction of cyclin inhibitors p21 and p27 (Taipale \& Beachy 2001, Sanchez et al. 2005). Our present study demonstrated that CP was capable of inhibiting cell cycle progression, DNA replication, and cell proliferation in KAT-18 and WRO82 cells. Additionally, our 
preliminary study suggests that CP may inhibit KAT18 cell proliferation in part by inducing apoptosis. SW1736 cells, a BRAF-mutated anaplastic thyroid tumor cell line, were less sensitive to CP- or HhAntagmediated cell proliferation. In contrast, we found that $S H H$ and $G L I 1$ knockdown led to a significant inhibition of cell proliferation of SW1736 cells. We speculate that the mild cytotoxicity of transfection agent may have enhanced the inhibitory effect of $\mathrm{SHH}$ and GLII knockdown on the proliferation of SW1736 cells. Nevertheless, we found that $S H H$ and GLII knockdown in KAT-18 cells also led to the inhibition of cell proliferation.

The inhibitors of the Hh pathway are currently being tested and developed as novel therapeutic agents for many malignancies with SHH pathway activation. Demonstration of the widespread expression of the molecules of the SHH pathway in thyroid neoplasms and activation of the SHH pathway in thyroid tumor cell lines suggests that the SHH pathway could serve as the early transformation marker as well as a potential molecular target for treatment of thyroid cancers, at least for some if not all.

\section{Declaration of interest}

The authors declare that there is no conflict of interest that could be perceived as prejudicing the impartiality of the research reported.

\section{Funding}

This work was supported in part by the ThyCa Foundation $(\mathrm{X} \mathrm{Xu})$ and the University Council of Research of Rush University Medical Center (C C Solorzano).

\section{Author contribution statement}

$\mathrm{X} \mathrm{Xu}$ initiated and implemented the execution of the research project, designed the experiments, analyzed and interpreted the data, and wrote the manuscript; H Ding, C P Saclarides, and J Esparaz conducted immunohistochemical and immunofluorescence staining; G Rao conducted cell culture and proliferation experiments; S Arora analyzed clinical data; P Gattuso provided slides and interpreted pathological data; C C Solorzano and R A Prinz conducted clinical data analysis, designed the experiments, and reviewed the manuscript.

\section{Acknowledgements}

We thank Drs Guy J F Juillard (University of California at Los Angeles) and Kenneth B Ain (University of Kentucky Medical Center, Lexington, KY, USA) for kindly providing three thyroid tumor cell lines. GDC-0449 was kindly provided by Genentech, Inc., South San Francisco.

\section{References}

Ain K, Taylor K, Rofiq S \& Venkataraman G 1997 Somatostatin receptor subtype expression in human thyroid and thyroid carcinoma cell lines. Journal of Clinical Endocrinology and Metabolism 82 1857-1862. (doi:10.1210/jc.82.6.1857)

Berman DM, Karhadkar SS, Maitra A, Montes De Oca R, Gerstenblith MR, Briggs K, Parker AR, Shimada Y, Eshleman JR, Watkins DN et al. 2003 Widespread requirement for Hedgehog ligand stimulation in growth of digestive tract tumours. Nature 425 846-851. (doi:10.1038/nature01972)

Bigelow RL, Chari NS, Unden AB, Spurgers KB, Lee S, Roop DR, Toftgard R \& McDonnell TJ 2004 Transcriptional regulation of bcl-2 mediated by the sonic hedgehog signaling pathway through gli-1. Journal of Biological Chemistry 279 1197-1205. (doi:10.1074/jbc. M310589200)

van den Brink GR 2007 Hedgehog signaling in development and homeostasis of the gastrointestinal tract. Physiological Reviews 87 1343-1375. (doi:10.1152/physrev.00054. 2006)

Burstein DE, Nagi C, Wang BY \& Unger P 2004 Immunohistochemical detection of p53 homolog p63 in solid cell nests, papillary thyroid carcinoma, and Hashimoto's thyroiditis: a stem cell hypothesis of papillary carcinoma oncogenesis. Human Pathology 35 465-473. (doi:10.1016/j.humpath.2003.10.027)

Caserta TM, Kommagani R, Yuan Z, Robbins DJ, Mercer CA \& Kadakia MP 2006 p63 overexpression induces the expression of Sonic Hedgehog. Molecular Cancer Research 4 759-768. (doi:10.1158/1541-7786.MCR-05-0149)

Chen X, Horiuchi A, Kikuchi N, Osada R, Yoshida J, Shiozawa T \& Konishi I 2007 Hedgehog signal pathway is activated in ovarian carcinomas, correlating with cell proliferation: it's inhibition leads to growth suppression and apoptosis. Cancer Science 98 68-76. (doi:10.1111/j. 1349-7006.2006.00353.x)

Cohen EE, Rosen LS, Vokes EE, Kies MS, Forastiere AA, Worden FP, Kane MA, Sherman E, Kim S, Bycott P et al. 2008 Axitinib is an active treatment for all histologic subtypes of advanced thyroid cancer: results from a phase II study. Journal of Clinical Oncology 26 4708-4713. (doi:10.1200/JCO.2007.15.9566)

Duman-Scheel M, Weng L, Xin S \& Du W 2002 Hedgehog regulates cell growth and proliferation by inducing cyclin D and cyclin E. Nature 417 299-304. (doi:10.1038/ 417299a)

Feng YZ, Shiozawa T, Miyamoto T, Kashima H, Kurai M, Suzuki A, Ying-Song J \& Konishi I 2007 Overexpression of hedgehog signaling molecules and its involvement in the proliferation of endometrial carcinoma cells. Clinical Cancer Research 13 1389-1398. (doi:10.1158/10780432.CCR-06-1407)

Gupta-Abramson V, Troxel AB, Nellore A, Puttaswamy K, Redlinger M, Ransone K, Mandel SJ, Flaherty KT, Loevner LA, O’Dwyer PJ et al. 2008 Phase II trial of 
sorafenib in advanced thyroid cancer. Journal of Clinical Oncology 26 4714-4719. (doi:10.1200/JCO.2008.16. 3279)

Hooper JE \& Scott MP 2005 Communicating with Hedgehogs. Nature Reviews. Molecular Cell Biology 6 306-317. (doi:10.1038/nrm1622)

Ji Z, Mei FC, Xie J \& Cheng X 2007 Oncogenic KRAS activates hedgehog signaling pathway in pancreatic cancer cells. Journal of Biological Chemistry 282 14048-14055. (doi:10.1074/jbc.M611089200)

Karhadkar SS, Bova GS, Abdallah N, Dhara S, Gardner D, Maitra A, Isaacs JT, Berman DM \& Beachy PA 2004 Hedgehog signalling in prostate regeneration, neoplasia and metastasis. Nature 431 707-712. (doi:10.1038/ nature02962)

Kasperczyk H, Baumann B, Debatin KM \& Fulda S 2009 Characterization of sonic hedgehog as a novel NF-kappaB target gene that promotes NF-kappaB-mediated apoptosis resistance and tumor growth in vivo. FASEB Journal $\mathbf{2 3}$ 21-33. (doi:10.1096/fj.08-111096)

Kimura ET, Nikiforova MN, Zhu Z, Knauf JA, Nikiforov YE \& Fagin JA 2003 High prevalence of BRAF mutations in thyroid cancer: genetic evidence for constitutive activation of the RET/PTC-RAS-BRAF signaling pathway in papillary thyroid carcinoma. Cancer Research $\mathbf{6 3}$ 1454-1457.

Kondo T, Ezzat S \& Asa SL 2006 Pathogenetic mechanisms in thyroid follicular-cell neoplasia. Nature Reviews. Cancer 6 292-306. (doi:10.1038/nrc1836)

Kubo M, Nakamura M, Tasaki A, Yamanaka N, Nakashima H, Nomura M, Kuroki S \& Katano M 2004 Hedgehog signaling pathway is a new therapeutic target for patients with breast cancer. Cancer Research 64 6071-6074. (doi:10.1158/0008-5472.CAN-04-0416)

Lee SY, Han HS, Lee KY, Hwang TS, Kim JH, Sung IK, Park HS, Jin CJ \& Choi KW 2007 Sonic hedgehog expression in gastric cancer and gastric adenoma. Oncology Reports 17 1051-1055.

Liu MS, Yang PY \& Yeh TS 2007 Sonic hedgehog signaling pathway in pancreatic cystic neoplasms and ductal adenocarcinoma. Pancreas 34 340-346. (doi:10.1097/ mpa.0b013e3180333ab5)

Ma X, Sheng T, Zhang Y, Zhang X, He J, Huang S, Chen K, Sultz J, Adegboyega PA, Zhang H et al. 2006 Hedgehog signaling is activated in subsets of esophageal cancers. International Journal of Cancer 118 139-148. (doi:10.1002/ijc.21295)

Mas C \& Ruiz i Altaba A 2010 Small molecule modulation of HH-GLI signaling: current leads, trials and tribulations. Biochemical Pharmacology 80 712-723. (doi:10.1016/ j.bcp.2010.04.016)

Morton JP, Mongeau ME, Klimstra DS, Morris JP, Lee YC, Kawaguchi Y, Wright CV, Hebrok M \& Lewis BC 2007 Sonic hedgehog acts at multiple stages during pancreatic tumorigenesis. PNAS 104 5103-5108. (doi:10.1073/pnas. 0701158104)
Namba H, Nakashima M, Hayashi T, Hayashida N, Maeda S, Rogounovitch TI, Ohtsuru A, Saenko VA, Kanematsu T \& Yamashita S 2003 Clinical implication of hot spot BRAF mutation, V599E, in papillary thyroid cancers. Journal of Clinical Endocrinology and Metabolism $\mathbf{8 8}$ 4393-4397. (doi:10.1210/jc.2003-030305)

Nelson KK, Gattuso P, Xu X \& Prinz RA 2010 Expression of the sonic hedgehog pathway molecules in synchronous follicular adenoma and papillary carcinoma of the thyroid gland in predicting malignancy. Surgery 148 654-660; (discussion 660). (doi:10.1016/j.surg.2010.07.030)

Nolan-Stevaux O, Lau J, Truitt ML, Chu GC, Hebrok M, Fernandez-Zapico ME \& Hanahan D 2009 GLI1 is regulated through Smoothened-independent mechanisms in neoplastic pancreatic ducts and mediates PDAC cell survival and transformation. Genes and Development 23 24-36. (doi:10.1101/gad.1753809)

Preto A, Reis-Filho JS, Ricardo S \& Soares P 2002 P63 expression in papillary and anaplastic carcinomas of the thyroid gland: lack of an oncogenetic role in tumorigenesis and progression. Pathology, Research and Practice 198 449-454. (doi:10.1078/0344-0338-00281)

Reis-Filho JS, Preto A, Soares P, Ricardo S, CameselleTeijeiro J \& Sobrinho-Simoes M 2003 p63 expression in solid cell nests of the thyroid: further evidence for a stem cell origin. Modern Pathology 16 43-48. (doi:10.1097/01. MP.0000047306.72278.39)

Romer JT, Kimura H, Magdaleno S, Sasai K, Fuller C, Baines $\mathrm{H}$, Connelly M, Stewart CF, Gould S, Rubin LL et al. 2004 Suppression of the Shh pathway using a small molecule inhibitor eliminates medulloblastoma in Ptc1(+/-)p53(-/-) mice. Cancer Cell 6 229-240. (doi:10.1016/j.ccr.2004.08.019)

Ruiz i Altaba A, Sanchez P \& Dahmane N 2002 Gli and hedgehog in cancer: tumours, embryos and stem cells. Nature Reviews. Cancer 2 361-372. (doi:10.1038/nrc796) Sanchez P, Hernandez AM, Stecca B, Kahler AJ, DeGueme AM, Barrett A, Beyna M, Datta MW, Datta S \& Ruiz i Altaba A 2004 Inhibition of prostate cancer proliferation by interference with SONIC HEDGEHOG-GLI1 signaling. PNAS 101 12561-12566. (doi:10.1073/pnas. 0404956101)

Sanchez P, Clement V \& Ruiz i Altaba A 2005 Therapeutic targeting of the Hedgehog-GLI pathway in prostate cancer. Cancer Research 65 2990-2992. (doi:10.1158/ 0008-5472)

Schweppe RE, Klopper JP, Korch C, Pugazhenthi U, Benezra M, Knauf JA, Fagin JA, Marlow LA, Copland JA, Smallridge RC et al. 2008 Deoxyribonucleic acid profiling analysis of 40 human thyroid cancer cell lines reveals cross-contamination resulting in cell line redundancy and misidentification. Journal of Clinical Endocrinology and Metabolism 93 4331-4341. (doi:10.1210/jc.2008-1102)

Stecca B, Mas C, Clement V, Zbinden M, Correa R, Piguet V, Beermann F \& Ruiz IAA 2007 Melanomas require 
HEDGEHOG-GLI signaling regulated by interactions between GLI1 and the RAS-MEK/AKT pathways. PNAS 104 5895-5900. (doi:10.1073/pnas.0700776104)

Taipale J \& Beachy PA 2001 The Hedgehog and Wnt signalling pathways in cancer. Nature 411 349-354. (doi:10.1038/35077219)

Teh MT, Wong ST, Neill GW, Ghali LR, Philpott MP \& Quinn AG 2002 FOXM1 is a downstream target of Gli1 in basal cell carcinomas. Cancer Research 62 4773-4780.

Thayer SP, di Magliano MP, Heiser PW, Nielsen CM, Roberts DJ, Lauwers GY, Qi YP, Gysin S, Fernandez-del Castillo C, Yajnik V et al. 2003 Hedgehog is an early and late mediator of pancreatic cancer tumorigenesis. Nature 425 851-856. (doi:10.1038/nature02009)

Unden AB, Zaphiropoulos PG, Bruce K, Toftgard R \& Stahle-Backdahl M 1997 Human patched (PTCH) mRNA is overexpressed consistently in tumor cells of both familial and sporadic basal cell carcinoma. Cancer Research 57 2336-2340.

Unger P, Ewart M, Wang BY, Gan L, Kohtz DS \& Burstein DE 2003 Expression of p63 in papillary thyroid carcinoma and in Hashimoto's thyroiditis: a pathobiologic link? Human Pathology 34 764-769. (doi:10.1016/ S0046-8177(03)00239-9)

Von Hoff DD, Lorusso PM, Rudin CM, Reddy JC, Yauch RL, Tibes R, Weiss GJ, Borad MJ, Hann CL, Brahmer JR et al. 2009 Inhibition of the hedgehog pathway in advanced basal-cell carcinoma. New England Journal of Medicine 361 1164-1172. (doi:10.1056/NEJMoa0905360)

Wang LH, Choi YL, Hua XY, Shin YK, Song YJ, Youn SJ, Yun HY, Park SM, Kim WJ, Kim HJ et al. 2006 Increased expression of sonic hedgehog and altered methylation of its promoter region in gastric cancer and its related lesions. Modern Pathology 19 675-683. (doi:10.1038/ modpathol.3800573)

Xie J, Murone M, Luoh SM, Ryan A, Gu Q, Zhang C, Bonifas JM, Lam CW, Hynes M, Goddard A et al. 1998 Activating Smoothened mutations in sporadic basal-cell carcinoma. Nature 391 90-92. (doi:10.1038/ 34201)

Xu X, Quiros RM, Gattuso P, Ain KB \& Prinz RA 2003 High prevalence of BRAF gene mutation in papillary thyroid carcinomas and thyroid tumor cell lines. Cancer Research 63 4561-4567.

Yauch RL, Gould SE, Scales SJ, Tang T, Tian H, Ahn CP, Marshall D, Fu L, Januario T, Kallop D et al. 2008 A paracrine requirement for hedgehog signalling in cancer. Nature 455 406-410. (doi:10.1038/nature07275)

Yuan Z, Goetz JA, Singh S, Ogden SK, Petty WJ, Black CC, Memoli VA, Dmitrovsky E \& Robbins DJ 2007 Frequent requirement of hedgehog signaling in non-small cell lung carcinoma. Oncogene 26 1046-1055. (doi:10.1038/sj.onc. 1209860)

Zhang X, Harrington N, Moraes RC, Wu MF, Hilsenbeck SG \& Lewis MT 2009 Cyclopamine inhibition of human breast cancer cell growth independent of Smoothened (Smo). Breast Cancer Research and Treatment 115 505-521. (doi:10.1007/s10549-008-0093-3)

Received in final form 21 December 2011

Accepted 12 January 2012

Made available online as an Accepted Preprint 12 January 2012 